\title{
A Legislação Trabalhista como Regime Jurídico do Funcionário Público
}

\author{
Philadelpho Pinto da Silveira
}

Assistente Juridico do Ministério do Exército

$\mathrm{D}_{\mathrm{s}}$

E acôrdo com as determinações expressas do Decreto-lei nú mero 4.114, de 14 de fevereiro de 1942, ao pessoal extranumerário das emprêsas de propriedade da União Federal ou por esta administradas, não se aplicava a legislação de proteção ao trabalho, regendo suas relações com o Govêrno Federal o Decreto-lei n²40, de 4 de fevereiro de 1938, e leis subseqüentes, e as questões resultantes das relações de trabalho entre aquêle pessoal e as respectivas emprêsas seriam dirimidas por leis administrativas, com recurso para a Justiça Ordinária.

A primeira tentativa no sentido de introduzir-se a legislação trabalhista como regime jurídico do servidor público surgiu com o advento da Lei $n^{\circ} 1.890$, de 13 de junho de 1953, que mandava aplicar aos mensalistas e diaristas da União, dos Estados, do Distrito Federal, dos Territórios e das entidades autárquicas, que trabalhassem nas suas organizações econômicas comerciais ou industriais em forma de emprêsa e não fôssem funcionários públicos ou não gozassem de garantias especiais, vários dispositivos da Consolidação das Leis do Trabalho.

No plano federal, desde logo se mostrou de nenhuma valia, por isso que o pessoal empregado naquelas atividades era constituído de extranumerários, admitidos de acôrdo com as disposições dos arts. 19 e 51, do Decerto-lei n' 284 , de 28 de outubro de 1938, disciplinadas pela de $n^{\circ} 240$, de 4 de fevereiro de 1938 .

Se, na forma do seu art. 54, o regime juridico dos funcionários piblicos thes era aplicado de maneira restrita, - apenas férias, licenças e consignações, o poder público negou-se a lhes proporcionar um regime próprio, talvez baseado no pressuposto de que

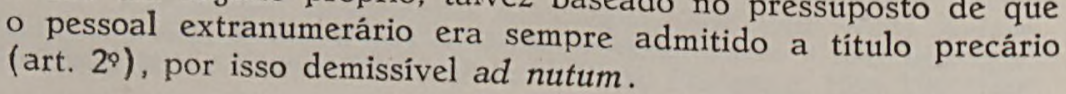


Uma vez desvirtuada a finalidade da criação do pessoal extranumerário, naturalmente aquilo que inicialmente lhe fôra negado, espontâneamente começou a lhe ser conferido, como verdadeira imposição da conjuntura.

Veio o instituto da Aposentadoria, através do Decreto-lei n? 3.768 , de 28 de outubro de 1941, e, já em 1943, o Decreto-lei $n^{\circ} 5.175$, de 7 de janeiro, estendia ao extranumerário as normas do Estatuto dos Funcionários Públicos Civis da União, referentes aos deveres e ação disciplinar. Com êle também vieram os institutos da Transferência, da Readmissão e da Reversão. O Decretolei $n^{\circ} 6.631$, de 27 de julho de 1944 , disciplinou a concessão de licenças e férias; o de $\mathrm{n}^{\circ} \mathbf{7 . 5 0 2}$, de 30 de abril de 1945, estendeu mais uma vantagem estatutária - a concessão de diárias; o de $\mathrm{n}^{\circ}$ 9.166, de 12 de abril de 1946, permitiu-lhes o exercicio de cargo de provimento em comissão, e o de $n^{\circ} 9.400$, de 21 de julho de 1946, a concessão de auxilio-funeral.

A Constituição de 1946, através do seu Ato das Disposições Constitucionais Transitórias, euqiparou aos funcionários aquêles que vinham exercendo funções de natureza permanente há mais de cinco anos, ou foram admitidos em virtude de concurso ou prova de habilitação, para efeito de estabilidade, aposentadoria, licença, disponibilidade e férias.

Até a interinidade foi aplicada ao pessoal extranumerário pelo Decreto $n^{\circ} 29.997$, de 14 de setembro de 1951 , sob o título de preenchimento provisório, com tôdas as características das disposições estatutárias.

Por final, o nôvo Estatuto, a Lei $n^{\circ} 1.711$, de 28 de outubro de 1952, em seu art. 252, estendeu o regime jurídico do funcionário aos extranumerários amparados pela Constituição de 1946, e aos demais extranumerários, no que couber.

Òbviamente, a Lei $n^{\circ} 1.890$, de 1953 , não atingiu as suas finalidades no serviço federal, porque já encontrou o pessoal a que se destinava perfeitamente equiparado aos funcionários públicos.

Dir-se-ia que o objetivo da lei era dar amparo àquele pessoal pago por economias administrativas, rendas próprias, fundo de serviço, etc. Todavia, também a êles se aplicam as conclusões do Parecer do DASP, ao apreciar o processo $n^{\circ} 5.895 / 52$, no sentido de que

"O serviço prestado à Justiça é inequivocamente serviço público em sentido lato. Se os serventuários judiciários não participam da qualidade de funcionários públicos stricto sensu, exercem, no entanto, função pública, 
na compreensão genérica do têrmo. Nem mesmo a circunstância de não perceberem remuneração dos cofres do Estado elimina a natureza publicista de suas ativida-
des".

O Plano de Classificação de Cargos do Serviço Civil do Poder Executivo veio pôr têrmo a quaisquer dúvidas, ao transformar em funcionário público todo aquêle pessoal, de modo que perderam a razão de ser as disposições do art. 257 do Estatuto.

Com efeito, a Lei $n^{\circ} 3.780$, de 12 de julho de 1960 , trouxe a esperança de que, reformuladas as bases estruturais do serviço público federal, estariam abertos os caminhos à Reforma Administrativa.

Não passaram despercebidas as necessidades de atendimento de serviços inadiáveis, técnicos ou de natureza temporária, e a lei disciplinou a matéria de modo excelente, em seu Capitulo VI.

Desta vez nova experiência se tenta em matéria de dar regime jurídico trabalhista ao pessoal que empresta sua colaboração ao serviço público federal, através do seu art. 24 , verbis,

"O pessoal temporário e o de obras ficarão sujeitos ao regime de emprêgo previsto na Consolidação das Leis do trabalho e na legislação vigente peculiar àquele regime de emprêgo",

compreendendo-se, por pessoal temporário, aquêle definido nos seus arts. $23, \mathrm{II}$, a, e 26 .

A matéria foi regulada pelo Decreto n 50.314 , de 4 de março de 1961 , que, em seu art. $5^{\circ}$, define a sujeição à legislação tra-
balhista.

Dois pontos ficaram bem claros na Lei - o pessoal temporário atenderá, tão-sòmente, às atividades de natureza transitória ou eventual, e o especialista temporário, às atividades técnico-especializadas, para cuja execução não disponha o serviço de funcionário habilitado, por prazo não excedente de um exercicio financeiro, de modo que o ato regulamentar, em setu art. 14, ao dispor que os contratos individuais de trabalho serão sempre por prazo determinado, deixou uma situação dúbia, que pode ensejar contratos renováveis ou por prazo superior a um ano.

Entretanto, se obedecida a lei, os frutos seriam os melhores possíveis. Lamentàvelmente, com honrosas exceç̃es, o administrador preferiu lançar mão do serviço de pessoal pago mediante recibo, para a execução de encargos de natureza permanente, o que atende à vocação empreguista do administrador pátrio, com pruridos da já ultrapassada época do spoil system. 
Assim, muito embora se afirme enfàticamente que tal situação não caracteriza relação de emprêgo (Decreto $n^{\circ}$ 50.314/61, parágrafo único do art. 3\%; Decreto $n^{\circ} 57.630$, de 14 de janeiro de 1966, art. 7\%; Decreto-lei n²00, de 25 de fevereiro de 1967, ar tigo 111), a Justiça do Trabalho, através de reiteradas decisões de suas Juntas, vem afirmando e confirmando o vínculo empregatício, o que é juridicamente correto.

Iniciada a Reforma Administrativa, além de não haver uniformidade de tratamento no que se refere ao pessoal das autarquias em extinção, supreendeu-nos a certeza de que a administração não se deu conta das implicações devidas à introdução do regime jurídico trabalhista no serviço público federal.

Com efeito, a Lei $n^{\circ} 5.173$, de 27 de outubro de 1966, ao extinguir a Superintendência do Plano de Valorização Econômica da Amazônia (SPVEA), dispõe que o seu pessoal poderá ser aproveitado na SUDAM; o näo aproveitado será distribuído aos demais órgãos da administração federal, impondo que

"O servidor do órgão extinto ao ser admitido pela SUDAM passa a reger-se pela Legislação Trabalhista e será considerado, em caráter excepcional, automàticamente licenciado de sua função pública, sem vencimentos, por esta, e, em prazo não excedente a 2 (dois) anos (art. 58)",

- que constitui modalidade não prevista no Estatuto dos Funcionários Públicos Civis da União, para depois manifestar sua opção.

Determina, ainda, aquêle diploma legal, que

"Esgotado o prazo de 2 (do:s) anos a contar da publicação desta lei, a SUDAM não poderá ter em sua lotação de servidores pessoal algum no gôzo da qualidade do funcionário público ( $§ 3^{\circ}$ do art. 59)".

O Decreto-lei $\mathrm{n}^{\circ} 161$, de 13 de fevereiro de 1967, ao criar a Fundação Instituto Brasileiro de Geografia e Estatística, considera em extinção dos quadros de pessoal dos órgãos da antiga autarquia, porém tomou o cuidado de salvaguardar, desde logo, os direitos dos seus ocupantes, estabelecendo as normas para o seu aproveitamento.

Também sem qualquer cobertura estatutária, prevê que os servidores pertencentes aos quadros em extinção, ou quaisquer servidores públicos ou autárquicos da União, poderão firmar contrato de trabalho com a Fundação, sob o regime da legislação trabalhista (arts. 19 a 22), suspensa a vinculação com o serviço público ... sem prazo determinado ... 
Extinto o Serviço de Alimentação da Previdência Social (SAPS), o Decreto-lei $n^{2} 224$, de 28 de fevereiro de 1967, resguardou os direitos do pessoal que servia à autarquia sob regime estatutário e prevê a redistribuição daqueles sob regime trabalhista, em órgão da administração centralizada ou autárquica da União Federal ( $\S 4^{\circ}$ do art. $\left.5^{\circ}\right)$.

Dispondo sôbre a administração do Instituto Nacional da Previdência Social, o Decreto-lei n²25, da mesma data, também considera gradativamente extintos os quadros de pessoal dos antigos Institutos, ressalvados os direitos dos seus ocupantes.

Estatui, em seu art. $6^{\circ}$, que o regime jurídico do pessoal do INPS será o da legislação trabalhista... mediante prévia habilitação em concurso público de provas ou de provas e titulos...

Aqui, também, se prevê a contratação de servidores autárquicos, sob regime trabalhista, suspensa a vinculação estatutária, sem prazo determinado.

Por seu turno, o Decreto $n^{\circ} 281$, de 28 de fevereiro dêste ano, ao extinguir o Instituto Nacional do Mate, simplesmente deixou ao Poder Executivo a tarefa de dispor sôbre o aproveitamento do seu pessoal.

Para não alongar a exposição, temos, finalmente, a extinção da Superintendência do Plano de Valorização Econômica da Região da Fronteira Sudoeste do País, com a criação da SUDESUL, através do Decreto-lei $n^{\circ} 301$, daquela data, dispondo que o pessoal da extinta autarquia poderá ser aproveitado pela novel entidade, prevendo sôbre a redistribuição do que lhe não fôr necessário, permitindo, ainda, a contratação, mediante regime trabalhista, sob a esdrúxula modalidade de suspensão do regime estatutário, por prazo indeterminado.

Desde logo, evidencia-se que as inovações contrariam os próprios cânones estabelecidos no Decreto-lei n²00, de 1967, eis que, se as Fundações, equiparadas às Emprêsas Públicas, e às Sociedades de Economia Mista têm personalidade jurídica de direito privado, as Autarquias não a tem, por isso que se tratam de meros serviços autônomos que não perdem a natureza essencialmente publicista de atividade administrativa (art. $5^{\circ}$ ).

Destarte, repentinamente, vimos completamente subvertida a norma de atendimento do Serviço Civil do Poder Executivo, isto é,

"I - quando se trate de atividade permanente da administração, por funcionạ́rios: eventual:

II - quando se trate de atividade transitória ou 
a) por pessoal temporário admitido à contaj de dotação global, recurso próprio do serviço ou fundo especial criado em lei;

b) por pessoal de obras admitido para realização de obras públicas, durante sua execução (Lei n 3.780 , de 1960, art. 23)".

Diga-se de passagem, que o próprio Decreto-lei $n^{\circ} 200$, de 1967, é incoerente em suas disposições, pois, se de um lado dispõe que

"Nos têrmos da legislação trabalhista, poderão ser contratados especialistas para atender às exigências de trabalho técnico em institutos, órgãos de pesquisa e outras entidades especializadas da Administração Direta ou autárquica, segundo critérios que, para êsse fim, serão estabelecidos em regulamento",

permite que o funcionário possa optar pela mudança de regime jurídico, levando-nos a admitir que estariam revogadas as citadas disposições da Lei n 3.780, de 1960, pois, na verdade, temos hoje,

a) Pessoal permanente;

b) Pessoal permanente em quadros especiais;

c) Pessoal permanente sob regime trabalhista;

d) Pessoal eventual (art. 111) exercendo atividades de caráter permanente; $\mathrm{e}$ manente.

e) Pessoal temporário exercendo atividades de caráter per-

Tendo em vista as disposições constitucionais (arts. 119, I e 134), ficam, pois, os servidores públicos como que sujeitos a duas jurisdições, a Federal e a Trabalhista.

Por final, com vistas à Seção VII - Dos Funcionários Públicos, da vigente Constituição do Brasil, e o que estatui o seu art. 104 , verbis

"Aplica-se a legislação trabalhista aos servidores admitidos temporàriamente para obras, ou contratados para funções de natureza técnica ou especializada",

afigura-se-me que a introdução do regime jurídico trabalhista fora dos casos ali mencionados, quer na administração direta, quer na descentralizada, é òbviamente inconstitucional, precisando ser revista, a partir de 15 de março de 1967. 